\title{
A study on premenstrual syndrome symptoms and their association with sleep quality in nursing staff
}

\author{
Gauri Kore ${ }^{1}$, Heena Merchant ${ }^{2 *}$, Hiba Narvel ${ }^{1}$, Ajita Nayak ${ }^{3}$, Avinash De Sousa ${ }^{2}$
}

\author{
${ }^{1}$ MBBS Student, Seth G. S. Medical College and K. E. M, Hospital, Mumbai, Maharashtra, India \\ ${ }^{2}$ Department of Psychiatry, Lokmanya Tilak Municipal Medical College, Mumbai, Maharashtra \\ ${ }^{3}$ Department of Psychiatry, Seth G. S. Medical College and K. E. M. Hospital, Mumbai, Maharashtra, India
}

Received: 28 January 2019

Accepted: 05 March 2019

\author{
*Correspondence: \\ Dr. Heena Merchant, \\ E-mail: heenathedoc@gmail.com
}

Copyright: (C) the author(s), publisher and licensee Medip Academy. This is an open-access article distributed under the terms of the Creative Commons Attribution Non-Commercial License, which permits unrestricted non-commercial use, distribution, and reproduction in any medium, provided the original work is properly cited.

\begin{abstract}
Background: Symptoms in the premenstrual period can be debilitating and troublesome and impacts the general health of women. There is a dearth of studies examining the relationship between sleep quality and premenstrual symptoms in women, especially in Indian settings. The current study was conducted with the aim of looking at the frequency of premenstrual syndrome (PMS) in different age groups and the association of these symptoms with sleep quality in nursing staff.

Methods: The cross-sectional study involved 450 female nursing staff between 25- 50 years of age from various tertiary care hospitals who were administered the Premenstrual Tension Syndrome Rating Scale (PMTS) and Pittsburgh Sleep Quality Index (PSQI). The data was then statistically analyzed.

Results: The prevalence of premenstrual symptoms was found to be $85.6 \%$ amongst the participants (according to the ACOG criteria), while the proportion of females suffering from PMS (according to DSM IVTR criteria) was $36.5 \%$. A correlation analysis between total scores of PMTS and PSQI showed a positive, linear and significant association. Conclusions: The intensity of PMS was associated with reduction in sleep quality in present study. Further studies on PMS and sleep related parameters need to carry out in larger samples to give impetus to our findings.
\end{abstract}

Keywords: Premenstrual symptoms, Premenstrual tension syndrome rating scale (PMTS), Pittsburgh sleep quality index (PSQI), Sleep, Sleep quality

\section{INTRODUCTION}

Menstruation is a physiological phenomenon which has been related to multiple psychosocial elements. ${ }^{1}$ Three out of four women experience physical and mental symptoms before menstruation. ${ }^{2}$ Premenstrual syndrome (PMS) is used to describe an array of predictable physical, cognitive, affective, and behavioral symptoms that occur cyclically during the luteal phase of the menstrual cycle and resolve quickly in a few days at the onset of menstruation. ${ }^{3-5}$ Multiple factors like hormonal, genetic, psychosocial and lifestyle factors may be effective on development of PMS. ${ }^{6}$ PMS is an important problem that affects women and causes loss of labor, can affect quality of life, sleep quality, family relations and work productivity. ${ }^{7-11}$ Women with PMS frequently complain of poor sleep quality and many women report changes in sleep quality and sleep problems such as insomnia, hypersomnia and nightmares. ${ }^{12-14}$

There is a dearth of literature on PMS symptoms and sleep quality and there are insufficient studies on PMS symptoms and sleep quality. ${ }^{15}$ Due to this dearth of studies, especially in the Indian scenario, authors decided to study the association between sleep quality and PMS symptoms. The study was conducted in nurses from two 
tertiary general hospitals as the sample would be similar in work load and stressors.

\section{METHODS}

This was a cross-sectional study conducted in nursing staff aged 25-50 years and working in two tertiary general hospitals i.e. K.E.M. Hospital and Lokmanya Tilak Municipal General Hospital, Mumbai. Institutional ethics committee was obtained for the study. Nursing staff were approached directly to obtain information for the same and one on one interviews were conducted. Written and valid informed consent was taken prior to the study.

\section{Inclusion criteria}

- Nursing staff between the age of 20-50 years that were having a regular menstrual cycle.

\section{Exclusion criteria}

- Nursing staff on hormonal therapy and oral contraceptives.

Nursing staff which major gynecological problems that would affect menstruation were also excluded from the study. The minimum optimum sample size obtained by using appropriate statistical formula resulted to be 440 . As the total number of nurses in K.E.M. Hospital was found to be twice of that in the other center, authors decided on 450 as a sample size with 300 nurses from K.E.M. Hospital and 150 from Lokmanya Tilak Municipal General Hospital.

The questionnaires used for the study were:

Premenstrual Tension Syndrome Observer Rating Scale (PMTS): The scale includes 11 domains with a total maximum score of 40 . It has a reliability coefficient 0.97 and has been widely used in studies on PMS. ${ }^{16}$
Pittsburgh Sleep Quality Index (PSQI): The scale measures sleep quality and disturbance retrospectively over a 1-month period using self-reports. Although the PSQI has been used in a variety of populations, published psychometric data are limited. It has good internal consistency and construct validity and reliability coefficient of 0.8 has been reported. ${ }^{17}$

Both the scales were administered in a single setting to the participants.

\section{Statistical analysis}

Descriptive statistics with frequency and percentage representing categorical variables were used while mean and standard deviation was used for the continuous variables. The comparison of continuous variables was done using Spearman Rank Correlation or nominal scale Chi square test. The statistical analysis was doing using a software (Statistical Package for Social Sciences, version SPSS20 software).

\section{RESULTS}

The subjects were 450 nursing staff from both the centers which has in fact a total of 1130 nursing staff. Authors wanted an equal sample size from different age groups. Hence, authors interviewed 150 nursing staff each from three age groups viz. 25-35 years, 35-45 years and > 45 years across both centers. On assessing sociodemographic data, all the three age groups were well matched on the average age of menarche, number of children and regularity of the menstrual cycle.

Table 1 illustrates the mean scores on the PMTS and all its items in the three age groups. The maximum mean PMTS score 17.6 \pm 6.46 was found in age group 35-45 years. Depressed mood, affective lability, irritability and impaired concentration were symptoms that had higher scores across the age groups.

Table 1: Scores on PMTS scale across the three groups.

\begin{tabular}{|l|l|l|l|l|l|l|l|}
\hline & Age & 25-35 years & \multicolumn{3}{l|}{ 35-45 years } & \multicolumn{4}{c|}{ 45 years } \\
& Range & Mean & SD & Mean & SD & Mean & SD \\
\hline Total score of PMTS & $0-40$ & 10.67 & 4.67 & 17.6 & 6.46 & 10.67 & 4.01 \\
\hline Depressed mood & $0-4$ & 1.08 & 0.82 & 1.2 & 0.94 & 1.03 & 0.8 \\
\hline Anxiety/Tension & $0-4$ & 0.79 & 0.85 & 1.2 & 0.93 & 0.95 & 0.76 \\
\hline Affective lability & $0-4$ & 1.39 & 0.78 & 1.27 & 1.00 & 0.99 & 0.74 \\
\hline Irritability & $0-4$ & 1.35 & 0.82 & 1.28 & 0.95 & 1.01 & 0.77 \\
\hline Decreased interest & $0-4$ & 1.02 & 0.83 & 1.8 & 0.99 & 0.86 & 0.72 \\
\hline Concentration difficulties & $0-4$ & 1.21 & 0.82 & 1.25 & 0.90 & 0.91 & 0.76 \\
\hline Lack of energy & $0-4$ & 1.9 & 0.76 & 1.37 & 1.01 & 1.08 & 0.76 \\
\hline Eating habits & $0-2$ & 0.91 & 0.65 & 0.5 & 0.73 & 0.74 & 0.65 \\
\hline Sleeping habits & $0-2$ & 0.85 & 0.80 & 0.8 & 0.66 & 0.91 & 0.74 \\
\hline Overwhelmed & $0-4$ & 0.4 & 0.73 & 1.27 & 0.89 & 1.08 & 0.8 \\
\hline Physical symptoms & $0-4$ & 1.08 & 0.82 & 1.37 & 0.82 & 1 & 0.76 \\
\hline
\end{tabular}


Table 2 shows the severity of Premenstrual symptoms in the age groups graded as minimal (0-10), mild (11-20), moderate (21-30) and severe (31-40). None of the participants reported minimal symptoms. Most participants had mild symptoms in both the groups $(\mathrm{p}=0.0019)$.

Table 2: Severity of scores on the PMTS scale.

\begin{tabular}{|l|l|l|l|}
\hline Severity Scores on PMTS & $\begin{array}{l}\mathbf{2 5 - 3 5} \\
\text { years }\end{array}$ & $\begin{array}{l}\text { 35-45 } \\
\text { years }\end{array}$ & $\begin{array}{l}>\mathbf{4 5} \\
\text { years }\end{array}$ \\
\hline Mild (11-20) & 124 & 103 & 130 \\
\hline Moderate $(21-30)$ & 21 & 37 & 14 \\
\hline Severe $(31-40)$ & 5 & 10 & 6 \\
\hline$X^{2}=16.9615, p=0.0019$ (significant) & & \\
\hline
\end{tabular}

Spearman correlation analysis between total scores of PMTS and that of PSQI showed a positive correlation for all groups (Table 3).

Table 3: Correlation between PMTS and PSQI scores.

\begin{tabular}{|l|l|l|}
\hline Age group & $\begin{array}{l}\text { Correlation between PMTS and PSQI } \\
\text { scores } \\
\text { r value }\end{array}$ & p value \\
\hline 25-35 years & 0.317 & $<0.0001^{*}$ \\
\hline 35-45 years & 0.332 & $<0.0001^{*}$ \\
\hline$>$ 45 years & 0.406 & $<0.0001^{*}$ \\
\hline
\end{tabular}

\section{DISCUSSION}

In the study, when the mean age at menarche was calculated, it came out to be 12.55 (25-35 years), 12.41 (35-45 years) and 12.05 (>45 years). In a study conducted in school girls aged 6-17 years, the mean age of menarche was found to be 12.4 years which is very close to our finding. ${ }^{18}$

In the current study, there was a positive significant correlation between total score of PMSS and scores of PSQI, which was in accordance with literature. In women with PMS, it has been noted the sleep quality worsened and as the PMS symptoms exacerbated, the sleep quality (except for the appetite change) negatively changed, as well. ${ }^{19}$ In a study on female students receiving education at a health high school, they determined a significantly poor sleep quality in $75.6 \%$ of subjects with PMS compared to $58.8 \%$ in girls without PMS. In the same study, a positive correlation was reported between total score of PMSS and mean score of PSQI. ${ }^{20}$

It has been reported in literature that experiencing the symptoms of bloating, fatigue, irritability, depressive thoughts and depressive affect more frequently in the premenstrual period maybe thus related to the poor sleep quality and the poor sleep quality could be exacerbating the premenstrual symptoms which constitutes a neverending vicious cycle. ${ }^{21}$ The current study has some limitations. It was cross sectional and done in a circumscribed population across 2 centers. Multiple factors that are confounding and that would affect the results of the study have not been evaluated. Both sleep and premenstrual symptoms have been influenced by a wide variety of factors that have not been considered in the study. Active intervention directed towards sleep quality and menstrual psychoeducation could improve performance at work and also reduce distress in nurses. Further studies on sleep parameters, menstruation and PMS are warranted in diverse populations.

\section{Funding: No funding sources}

Conflict of interest: None declared

Ethical approval: The study was approved by the Institutional Ethics Committee

\section{REFERENCES}

1. Dennerstein L, Lehert $\mathrm{P}$, Heinemann $\mathrm{K}$. Epidemiology of premenstrual symptoms and disorders. Menopause Int. 2012;18(2):48-51.

2. Selçuk KT, Avcı D, Yılmaz F. The prevalence of premenstrual syndrome among nursing students and affecting factors. J Psychiatr Nurs. 2014;5(2):98-103.

3. Erbil N, Karaca A, Kırış T. Investigation of premenstrual syndrome and contributing factors among university students. Turk J Med Sci. 2010;40(4):565-73.

4. Direkvand-Moghadam A, Sayehmiri K, Delpisheh A, Kaikhavandi S. Epidemiology of Premenstrual Syndrome (PMS)-A systematic review and metaanalysis study. J Clin Diagn Res. 2014;8(2):106-11.

5. Angst J, Sellaro R, Stolar M, Merikangas KR, Endicott J. The epidemiology of perimenstrual psychological symptoms. Acta Psychiatr Scand. 2001;104(2):110-6.

6. Nisar N, Zehra N, Haider G, Munir AA, Sohoo NA. Frequency, intensity and impact of premenstrual syndrome in medical students. J Coll Physicians Surg Pak. 2008;18(8):481-4.

7. Borenstein J, Chiou CF, Dean B, Wong J, Wade S. Estimating direct and indirect costs of premenstrual syndrome. J Occup Environ Med. 2005;47(1):26-33.

8. Rapkin AJ, Winer SA. Premenstrual syndrome and premenstrual dysphoric disorder: quality of life and burden of illness. Exp Rev Pharmacoecon Outcomes Res. 2009;9(2):157-70.

9. Ozisik Karaman HI, Tanriverdi G, Degirmenci Y. Subjective sleep quality in premenstrual syndrome. Gynecol Endocrinol. 2012;28(8):661-4.

10. Borenstein JE, Dean BB, Endicott J, Wong J, Brown C, Dickerson V, Yonkers KA. Health and economic impact of the premenstrual syndrome. J Reprod Med. 2003;48(7):515-24.

11. Chawla A, Swindle R, Long S, Kennedy S, Sternfeld B. Premenstrual dysphoric disorder: is there an economic burden of illness?. Med Care. 2002;11(3):1101-12.

12. Baker FC, Kahan TL, Trinder J, Colrain IM. Sleep quality and the sleep electroencephalogram in 
women with severe premenstrual syndrome. Sleep. 2007;30(10):1283-91.

13. Biggs WS, Demuth RH. Premenstrual syndrome and premenstrual dysphoric disorder. Amer Fam Physician. 2011;84(8):918-26.

14. Braverman PK. Premenstrual syndrome and premenstrual dysphoric disorder. J Pediatr Adolesc Gynaecol. 2007;20(1):3-12.

15. Ozisik Karaman HI, Tanriverdi G, Degirmenci Y. Subjective sleep quality in premenstrual syndrome. Gynecol Endocrinol. 2012;28(8):661-4.

16. Steiner M, Peer M, Macdougall M, Haskett R. The premenstrual tension syndrome rating scales: an updated version. J Affect Disord. 2011;135(1-3):828.

17. Buysse DJ, Reynolds III CF, Monk TH, Berman SR, Kupfer DJ. The Pittsburgh Sleep Quality Index: a new instrument for psychiatric practice and research. Psychiatr Res. 1989;28(2):193-213.

18. Steiner M, Dunn E, Born L. Hormones and mood: from menarche to menopause and beyond. J Affect Disord. 2003;74(1):67-83.
19. Baker FC, Colrain IM, Trinder J. Reduced parasympathetic activity during sleep in the symptomatic phase of severe premenstrual syndrome. J Psychosom Res. 2008;65(1):13-22.

20. de Zambotti M, Nicholas CL, Colrain IM, Trinder JA, Baker FC. Autonomic regulation across phases of the menstrual cycle and sleep stages in women with premenstrual syndrome and healthy controls. Psychoneuro Endocrinol. 2013;38(11):2618-27.

21. Baker FC, Driver HS. Circadian rhythms, sleep, and the menstrual cycle. Sleep Med. 2007;8(6):613-22.

Cite this article as: Kore $\mathrm{G}$, Merchant $\mathrm{H}$, Narvel $\mathrm{H}$, Nayak A, Sousa AD. A study on premenstrual syndrome symptoms and their association with sleep quality in nursing staff. Int J Reprod Contracept Obstet Gynecol 2019;8:1487-90. 